\title{
The Effect of Antihypertensive Drugs on Endothelial Function as Assessed by Flow-Mediated Vasodilation in Hypertensive Patients
}

\author{
Michiaki Miyamoto, ${ }^{1,2}$ Kazuhiko Kotani, ${ }^{1}$ Shun Ishibashi, ${ }^{2}$ and Nobuyuki Taniguchi' \\ ${ }^{1}$ Department of Clinical Laboratory Medicine, Jichi Medical University, 3311-1 Yakushiji, Shimotsuke-City, Tochigi 329-0498, Japan \\ ${ }^{2}$ Division of Endocrinology and Metabolism, Department of Medicine, Jichi Medical University, 3311-1 Yakushiji, Shimotsuke-City, \\ Tochigi 329-0498, Japan
}

Correspondence should be addressed to Kazuhiko Kotani, kazukotani@jichi.ac.jp

Received 11 September 2011; Revised 22 November 2011; Accepted 23 December 2011

Academic Editor: Tomoki Hashimoto

Copyright (c) 2012 Michiaki Miyamoto et al. This is an open access article distributed under the Creative Commons Attribution License, which permits unrestricted use, distribution, and reproduction in any medium, provided the original work is properly cited.

Endothelial dysfunction is found in hypertensive patients and may serve as a prognostic marker of future cardiovascular events. Endothelial function can be assessed noninvasively by flow-mediated vasodilation (FMD). The goal of this paper is to summarize comprehensively the clinical trials that investigated the effects of antihypertensive drugs on endothelial function assessed by FMD in hypertensive patients. A PubMed-based search found 38 clinical trial papers published from January 1999 to June 2011. Significant improvement of FMD after antihypertensive treatment was shown in 43 of 71 interventions (among 38 clinical trial papers). Angiotensin II receptor blockers and angiotensin converting enzyme inhibitors appeared to improve FMD more than other drug types. Antihypertensive treatment can improve endothelial dysfunction when assessed by FMD, although there are conflicting data that require further research.

\section{Introduction}

Atherosclerotic risk factors such as hypertension (HTN), diabetes mellitus, dyslipidemia, obesity, and smoking cause endothelial dysfunction [1-5]. Endothelial dysfunction occurs in the early stages of atherosclerosis and is involved in disease progression as well as the morbid cardiovascular events that often occur in advanced stages of the diseases [1-5]. The endothelium is involved in the control of the coagulation/fibrinolytic system, platelet aggregation, adhesion of leukocytes, and smooth muscle cell proliferation and is important in the maintenance of vascular tone $[1,3]$. The response-to-injury hypothesis, proposed by Russell Ross [6], states that atherosclerosis is due to an inflammatory reaction in response to endothelial injury or dysfunction and is supported by numerous basic and clinical investigations $[1,3]$.

The evaluation of endothelial function is available as a predictor of cardiovascular events and as a surrogate marker for early atherosclerosis $[1-3,7,8]$. There are several methods to evaluate endothelial function that include an invasive method using endothelium-dependent vasodilators injected into a coronary or peripheral artery [7], and flowmediated vasodilation (FMD), a noninvasive method based on endothelium-dependent arterial vasodilation $[9,10]$. FMD was first reported in 1992 by Celermajer et al., as an innovative method of detecting endothelial dysfunction [10]. The sudden release of an artery after transient occlusion causes an increase in shear stress on the vessel wall due to hyperemia and this stimulates endothelial cells to release various physiologically active substances. Nitric oxide (NO) is one of the main substances released by the endothelium and causes relaxation of vascular smooth muscle with a subsequent increase in vascular diameter [1]. FMD is measured from the expansion rate of arterial diameter during the postischemic hyperemia response. Since guidelines for the measurement of FMD have been established [9] and the measuring equipment has been improved, FMD is gaining acceptance as a simple, safe, and valuable method to evaluate endothelial function in clinical practice.

HTN is prevalent worldwide and one of the most important risk factors for atherosclerotic disease [11, 12]. The relationship between FMD and blood pressure has been reported in a general population $[13,14]$. FMD was 
inversely related to age, male gender, systolic blood pressure, body mass index, and smoking in the Framingham study [13]. It was inversely correlated with male gender, blood pressure, glucose, and directly with high-density lipoprotein cholesterol, C-reactive protein, and body mass index in healthy young adults (Young Finns study) [14]. Moreover, treatment of HTN leads to the prevention of atherosclerotic disease $[11,12]$. There are several types of antihypertensive drugs used to treat HTN, and several studies investigated the effect of antihypertensive medications on FMD. It is possible that the choice of the best drug to treat HTN in the future could be based on the magnitude of the improvement in endothelial function. This paper comprehensively summarizes the current knowledge from the clinical trials that have evaluated the effect of antihypertensive drugs on FMD in patients with HTN.

\section{Methodology of FMD}

Guidelines for the ultrasound assessment of endothelialdependent FMD of the brachial artery have been established [9]. There are still some issues with the reproducibility and objectivity of FMD measurements, because it is necessary to record very small changes in vascular diameter [9], and sonographers must receive adequate training and gain experience before they become competent with this technique. Subjects should fast for at least 8 to 12 hours before the measurement. In addition, subjects should not exercise, should not ingest substances that might affect FMD, such as caffeine, or use tobacco for at least 4 to 6 hours before the measurement.

FMD is assessed in a subject's right arm in the supine position in a quiet, temperature-controlled room. The brachial artery is imaged above the antecubital fossa in the longitudinal plane using B-mode ultrasound, and the diameter of the brachial artery is measured continuously. A cuff is placed either around the forearm or above the antecubital fossa. After a baseline, resting image is acquired, arterial occlusion is induced by cuff inflation to a pressure above the systolic pressure, typically to at least $50 \mathrm{mmHg}$ above systolic pressure for 5 minutes. When the cuff is released, FMD is calculated as the maximum percent increase in the diameter during hyperemia compared with the baseline diameter.

\section{Clinical Trials Using FMD}

Several studies were reviewed that investigated changes in FMD due to treatment in hypertensive patients. We selected 38 papers published from January 1999 to June 2011 using a PubMed-based search engine. The keywords used in the search were "flow-mediated vasodilation" and "hypertension", and the original articles were eligible. The appropriateness of all papers identified by the search was confirmed by two experts. When the trial designs of 38 clinical trial papers were classified by the method of Zaza et al. [15], there were 26 randomized controlled trials (RCTs), 5 controlled clinical trials (CCTs), and 7 single-arm trials that were selected (Table 1). The comparisons of multiple antihypertensive drugs were usually done in RCTs or CCTs, and 71 interventions with each antihypertensive drug were investigated in these 38 clinical trial papers. Significant improvement of FMD after antihypertensive treatment was shown in 43 of 71 interventions.

Medications that block the renin-angiotensinaldosterone system (RAAS) include angiotensin converting enzyme inhibitors (ACEIs) and angiotensin II receptor blockers (ARBs). These agents are effective in lowering blood pressure and result in organ protection that is effective for clinical conditions such as heart failure [12, 54], chronic kidney disease $[12,55]$, and diabetes mellitus $[12,56]$. As shown in Table 1, most studies have shown that ARBs and ACEIs could improve FMD. One RCT compared the effects of the ACEI enalapril $(5-40 \mathrm{mg} / \mathrm{day}, n=9)$ and the ARB losartan (50-100 mg/day, $n=9)$ on endothelial function in hypertensive patients [17]. Six months after treatment, FMD improved in both treatment groups compared with baseline levels. In another RCT, patients with HTN were given one of three different ARBs (losartan 50-100 mg/day, $n=31$; irbesartan 150-300 mg/day, $n=30$; candesartan $8-16 \mathrm{mg} /$ day, $n=31$ ) for 2 months, and the change in FMD was compared among the three groups. ARB therapy significantly improved FMD with no differences among the three groups [23]. The other RCT (cross-over design) also investigated the improvement of FMD during 3 months of treatment with a low or a high dose of ramipril (5 or $10 \mathrm{mg} /$ day, $n=46$ ) [28]. While both dosages of ramipril increased FMD, the increase of NO-dependent FMD using $\mathrm{N}^{\mathrm{G}}$-monomethyl-L-arginine to block $\mathrm{NO}$ synthase was greater with the high than with the low dose [28]. In another RCT, treatment with the calcium channel blocker (CCB) amlodipine ( $5 \mathrm{mg} /$ day, $n=22)$ did not change FMD as much as treatment with the ARB telmisartan $(40 \mathrm{mg} /$ day, $n=21$ ) for 24 weeks [24]. There were other similar RCTs that compared ACEIs or ARBs with CCBs (perindopril versus amlodipine [34], valsartan versus amlodipine [50], and olmesartan versus amlodipine [52]), and all of these trials showed that ARBs or ACEIs significantly improved FMD compared with CCBs.

The protective effect of CCBs on cardiovascular disease in hypertensive patients has been established in several largescale clinical trials $[12,57]$. However, RCTs which showed improvement of FMD were limited [16, 21, 24, 26, 31, 33, 34, 50, 52].

$\beta$-blockers have also an established role in cardioprotection $[12,54,58]$. Among various $\beta$-blockers, nebivolol is a selective $\beta$-1 adrenergic receptor antagonist and induces endothelial-dependent vasodilation [59]. One RCT compared the effect of nebivolol ( $5 \mathrm{mg} /$ day, $n=20)$ with atenolol ( $100 \mathrm{mg} /$ day, $n=20)$, a traditional selective $\beta-1$ adrenergic receptor blocker without vasodilating properties, on FMD in hypertensive patients [41]. At 4 weeks after treatment, FMD improved more with nebivolol than with atenolol. Furthermore, there were several trials that showed improvement of FMD by nebivolol compared with baseline $[36,43]$; however, this drug had less of an effect on FMD than other drug types.

Several RCTs compared three or more types of antihypertensive drugs [21, 23, 25, 29, 49]. One RCT investigated 


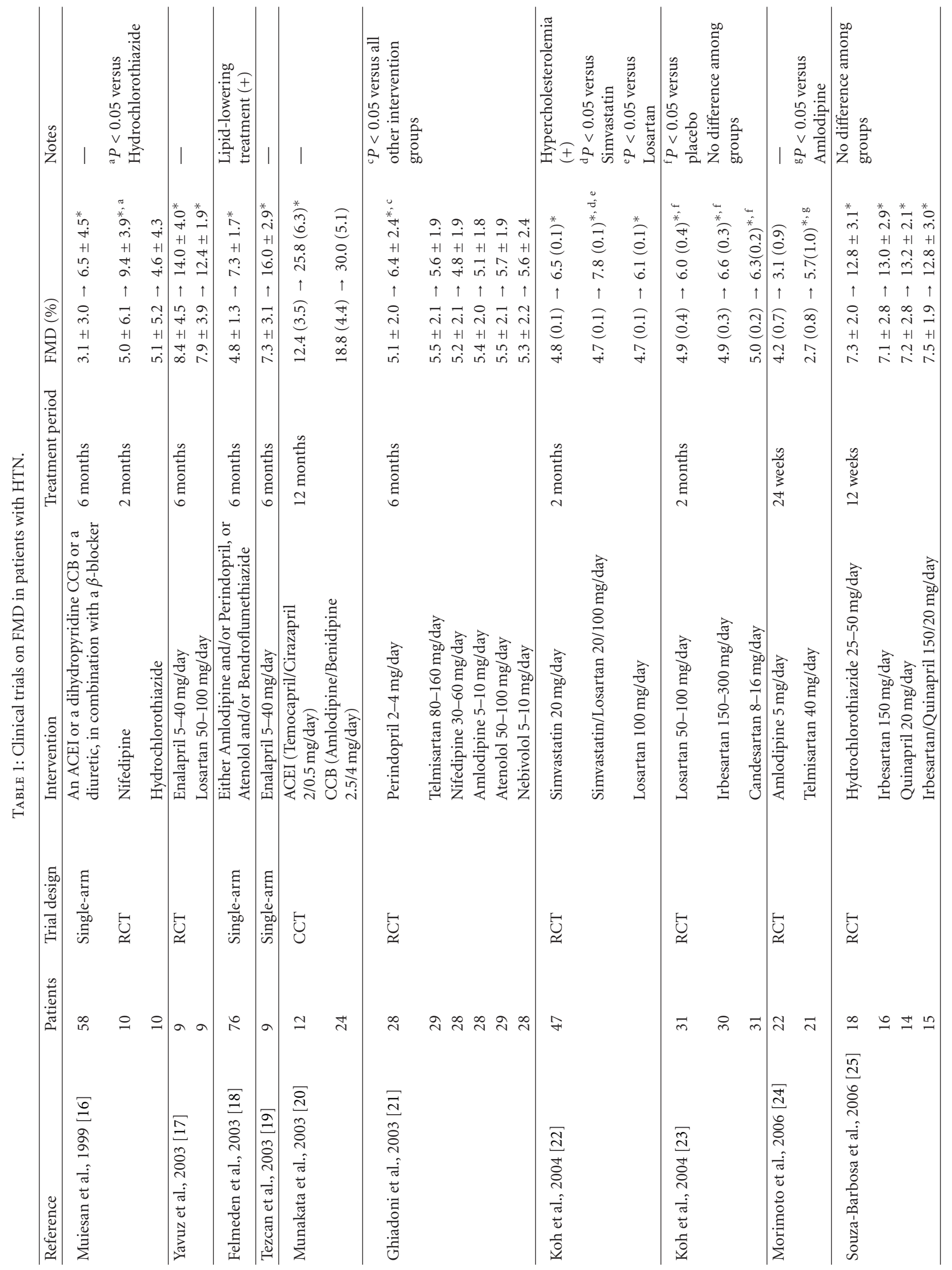




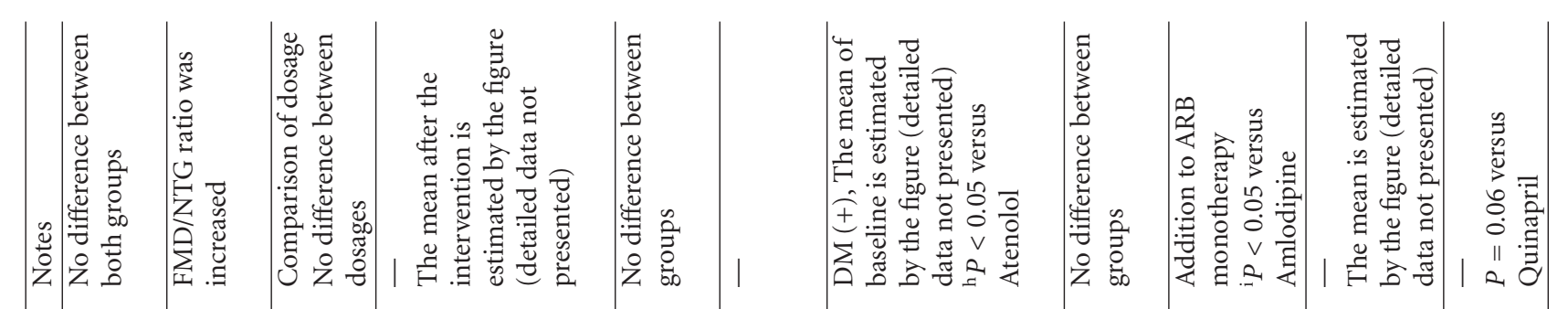

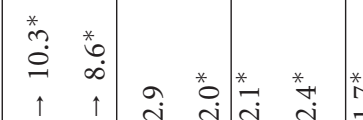

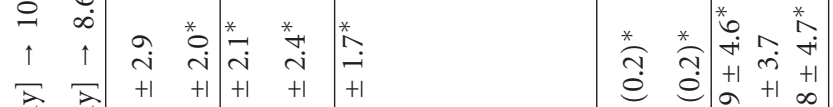

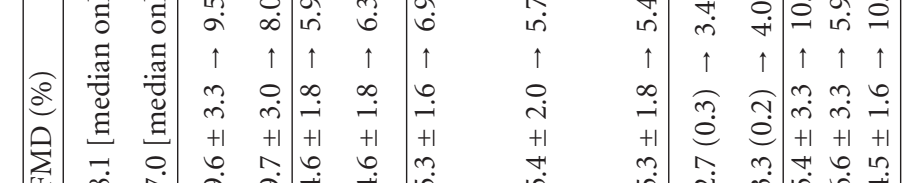

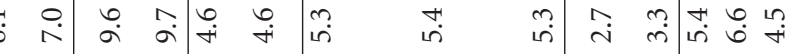
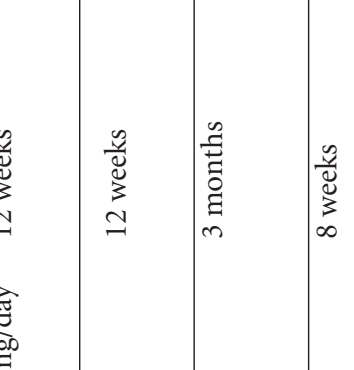

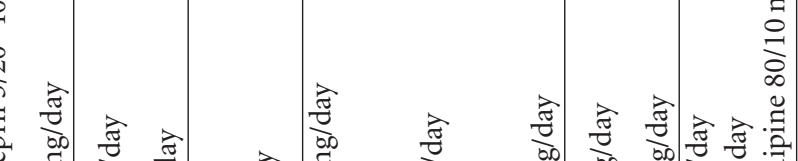

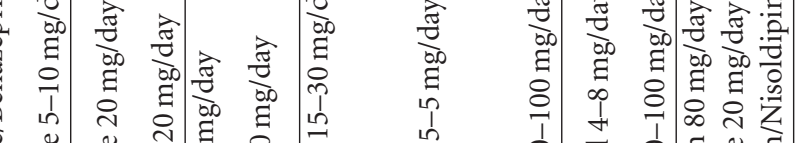

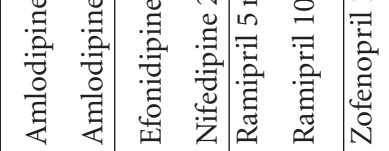
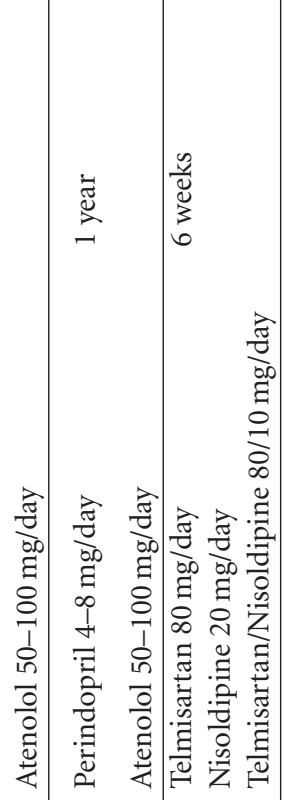

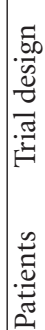

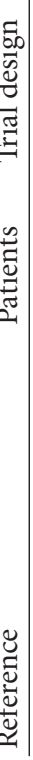

(2)

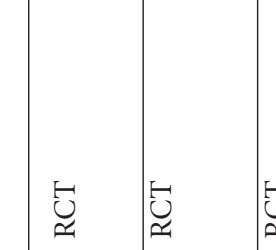

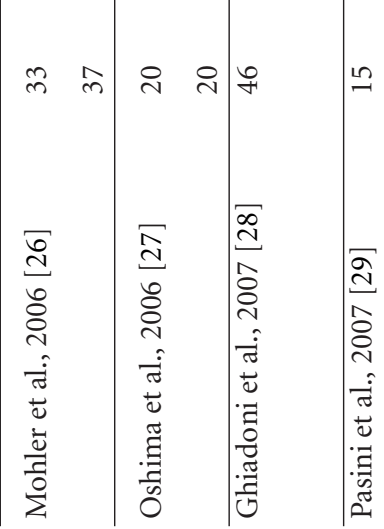
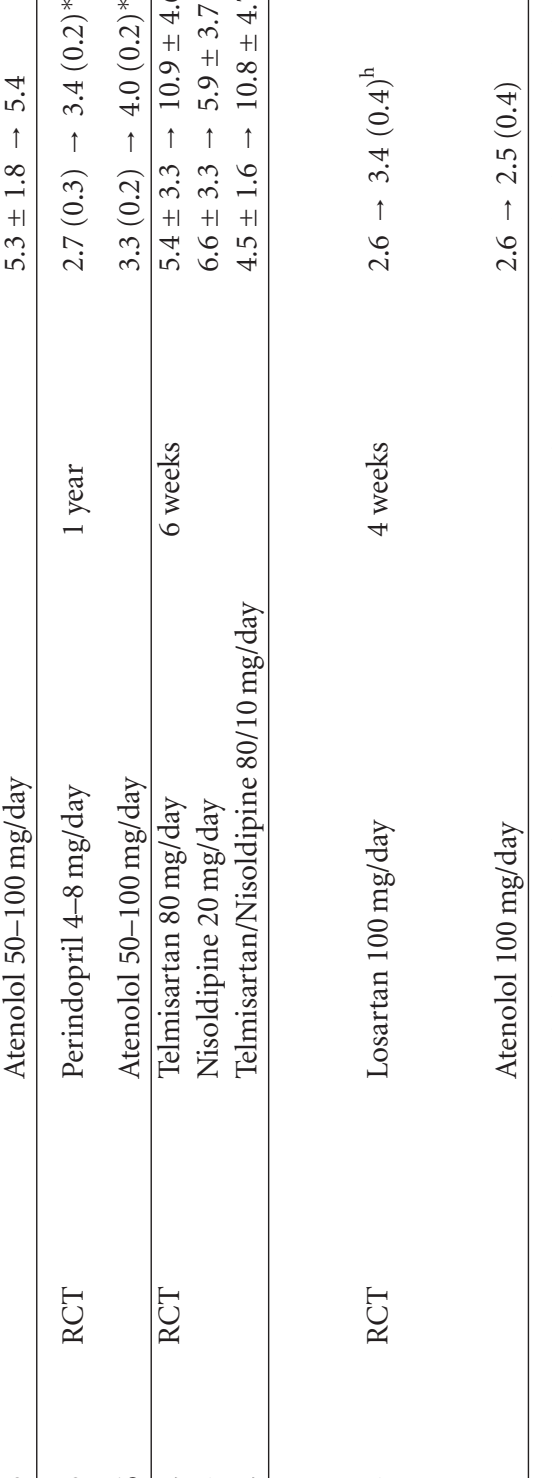

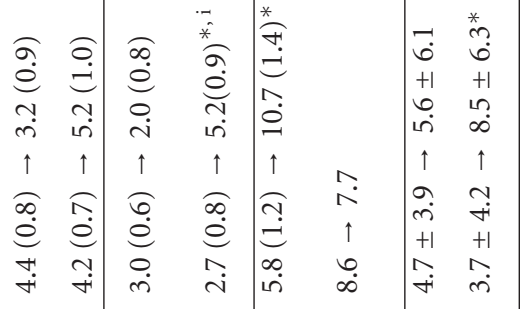

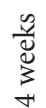

这

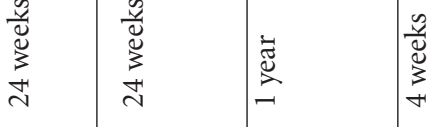

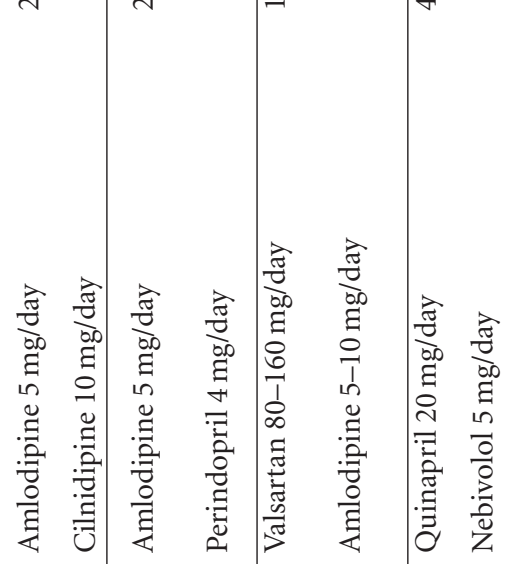

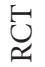

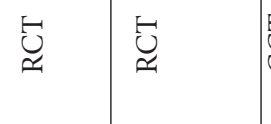

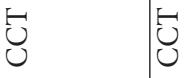

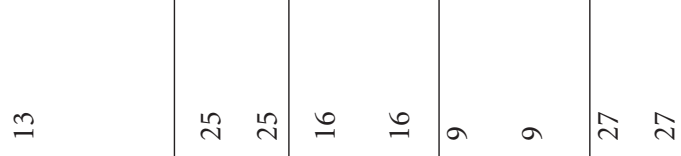




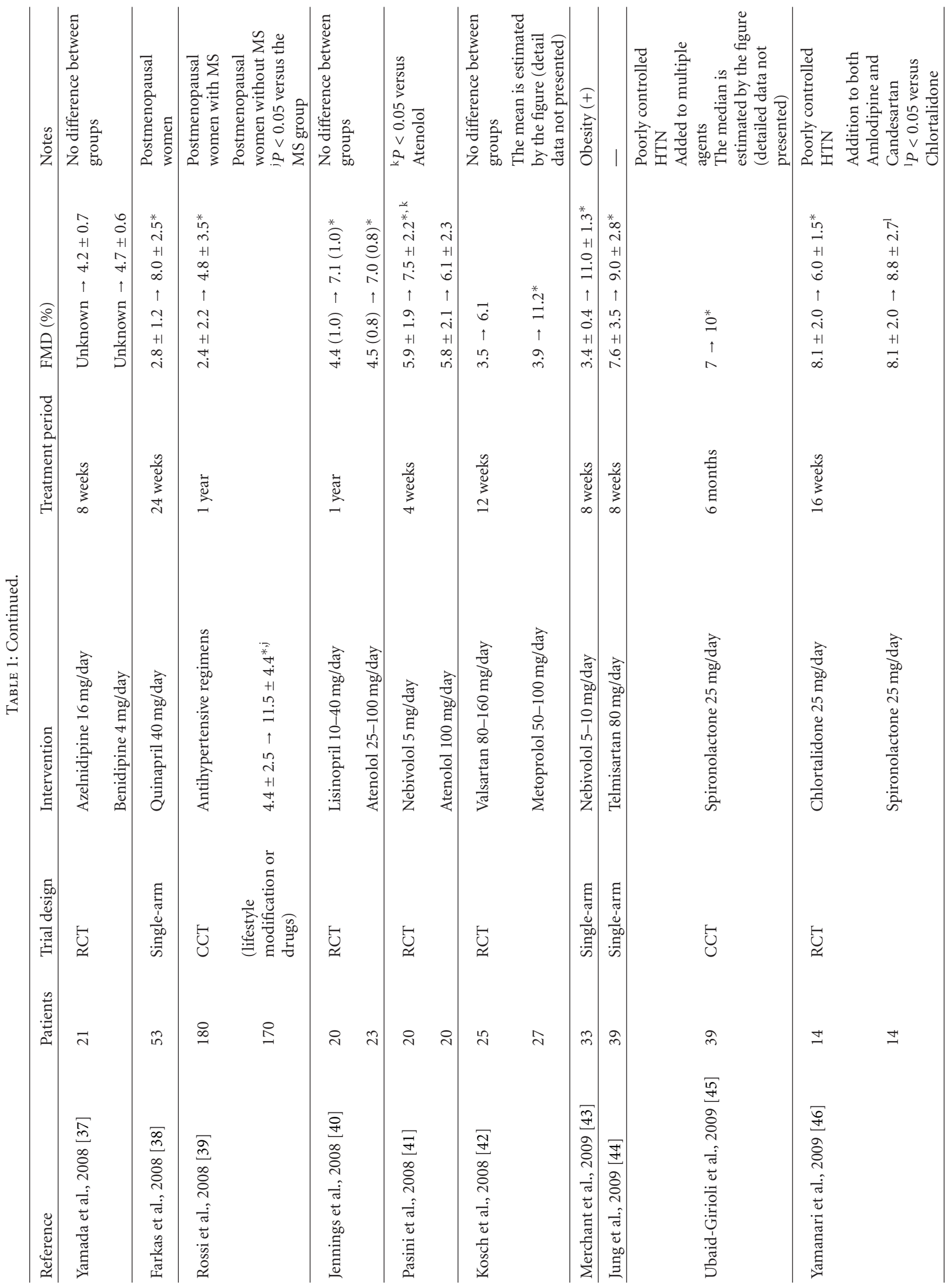




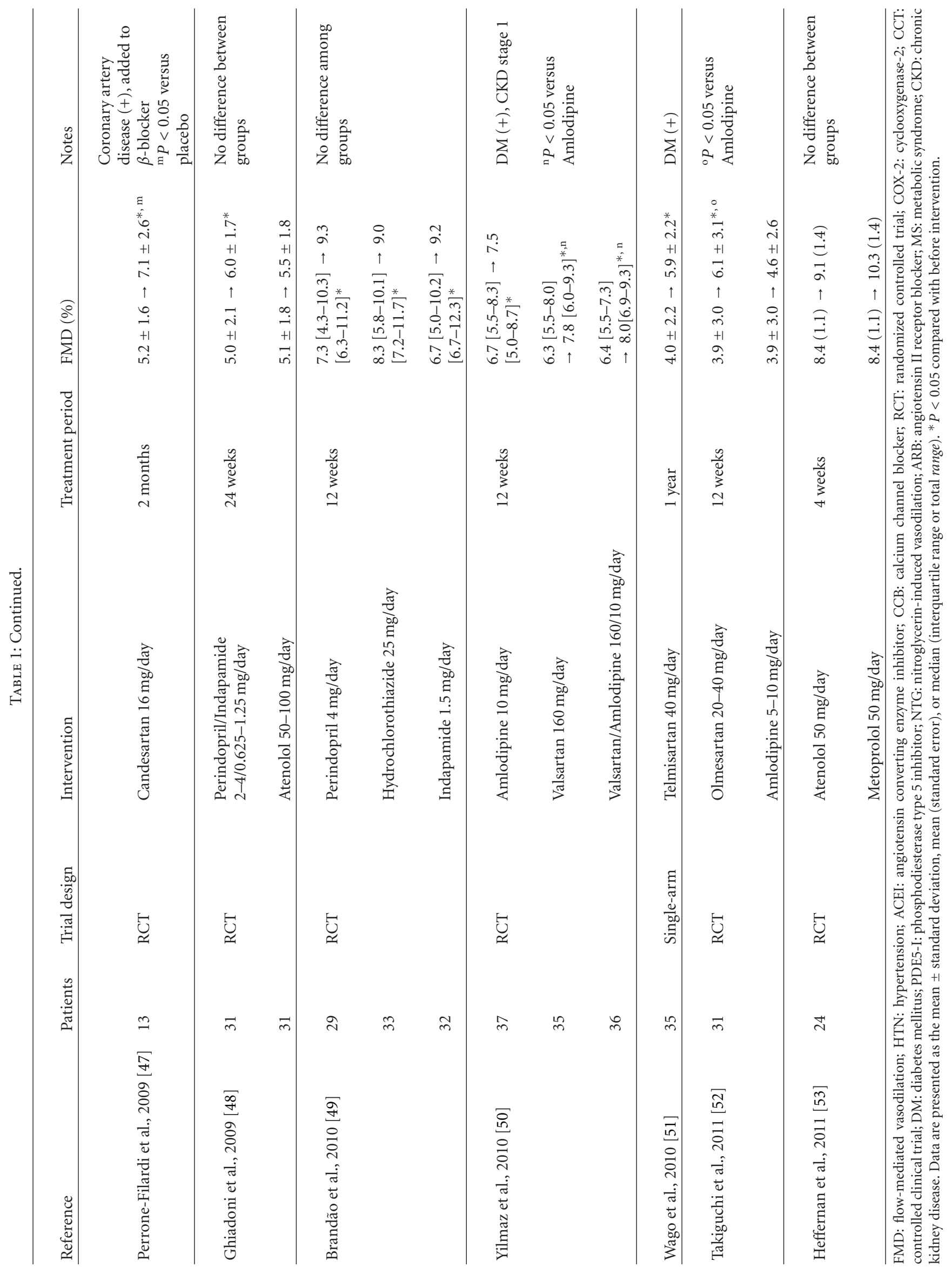




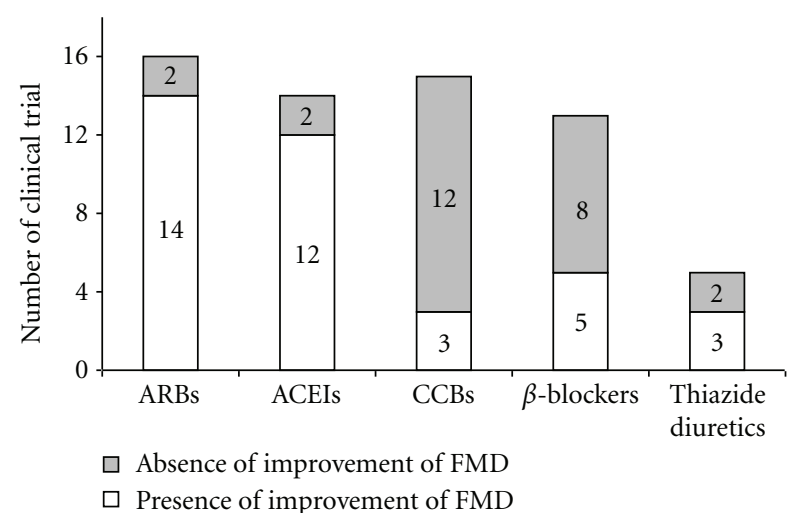

Figure 1: Columns indicate the number of clinical trials that showed the presence or the absence of significant improvement of flow-mediated vasodilation from baseline due to the intervention. FMD: flow-mediated vasodilation; ARBs: Angiotensin II receptor blockers; ACEIs: Angiotensin converting enzyme inhibitors; CCBs: Calcium channel blockers.

the effects of the ACEI perindopril ( $2-4 \mathrm{mg} / \mathrm{day}, n=28)$, the ARB telmisartan $(80-160 \mathrm{mg} /$ day, $n=29)$, the CCB, nifedipine (30-60 mg/day, $n=28$ ), the CCB amlodipine (5$10 \mathrm{mg} /$ day, $n=28)$, the $\beta$-blocker atenolol $(50-100 \mathrm{mg} /$ day, $n=29$ ), and the $\beta$-blocker nebivolol (5-10 $\mathrm{mg} /$ day, $n=28)$ on FMD [21]. Interestingly, only perindopril significantly improved FMD, whereas all the drugs reduced blood pressure to similar levels.

Furthermore, there was one study that examined the significance of FMD as a prognostic marker of cardiovascular events. Postmenopausal women $(n=400)$ with HTN and impaired FMD received 6 months of antihypertensive therapy (the choice of the antihypertensive drug used was at the discretion of the study investigators) and then were followed-up for a mean period of 67 months. After 6 months of treatment, 250 women showed significantly improved FMD, and this group had significantly fewer cardiovascular events compared with the group without improved FMD (there were no deaths from cardiac causes during the study period) [8].

A prospective study showed the relationship between a low level of FMD and cardiovascular events (although this study did not necessarily have an intervention) [60]. Hypertensive patients $(n=172)$ were divided into a lowand high-FMD group based on the median level of FMD and were followed for 95 months [60]. The incidence of cardiovascular events was 1.4 and 3.1 per 100 patient-years in the low and high groups, respectively. In a Cox proportional hazards analysis, the low-FMD group showed a 2.67 -fold increased risk of cardiovascular events [60].

Given the overall data, antihypertensive treatment can improve endothelial dysfunction when assessed by FMD. The results of clinical trials showing the effects of different drug types on change in FMD are summarized in Figure 1. More interventions that showed significant improvement of FMD appeared to be found in patients treated with ARBs and ACEIs than those treated with other drug types. However, this is not conclusive, because there has been no single RCT that compared the effects of all drug types on FMD.
Although discrepant results among trials remain to be resolved, they may have been due to differences in the characteristics of patients, the experimental design (i.e., cross-over or parallel group, and the duration of treatment in the intervention), the sample size (relating to the study power) and statistical methodology, and measurement issues (e.g., reproducibility of FMD) [61-63]. A previous study demonstrated that the coefficients of variation of FMD ranged from 6.6 to $10.6 \%$ in healthy adults that underwent repeated FMD at intervals of up to 3 months $(n=42$, mean age $=43$ ) [61]. Patients with atherosclerotic risk factors can also show decreased reproducibility of FMD due to the progression of atherosclerosis over time (e.g., with structural and functional changes of arteries) $[62,63]$.

\section{Mechanisms of the Improvement of FMD}

Endothelial dysfunction is generally caused by a reduction of endothelium-derived relaxing factors (EDRFs) such as NO, failure of smooth muscle cells to respond to EDRF, activation of the RAAS, and production of vasoconstrictors such as endothelin [1-5]. These factors are also influenced by vascular inflammation associated with oxidative stress [ $1-$ 5]. However, damaged endothelial cells can be replicated locally and develop into mature endothelial cells with normal function $[1,64,65]$. Circulating endothelial progenitor cells from bone marrow also participate in the repair of the endothelium $[1,64]$. The balance between endothelial impairment and repair is a major determinant of endothelial function. Of note, there have been trials that measured biochemical markers such as NO, oxidative stress, and inflammatory markers, in addition to $\operatorname{FMD}[17,18,22$, $23,27,29,31,32,35,37,38,41,43,44,46,49,51-53]$. One RCT compared the CCB azelnidipine $(16 \mathrm{mg} /$ day $)$ with the CCB benidipine ( $4 \mathrm{mg} /$ day) in a cross-over design with 8 weeks on each drug [37]. That study examined serum levels of NO and malonyldialdehyde low-density lipoprotein (MDA-LDL) and found that there was no difference in FMD or the levels of NO and MDA-LDL between the two drugs. Another cross-over RCT $(n=13,4$ weeks on each drug) compared the effects of losartan $(100 \mathrm{mg} /$ day $)$ and atenolol $(100 \mathrm{mg} /$ day $)$ on FMD and the levels of 8isoprostane, a marker of oxidative stress [32]. Losartan, but not atenolol, significantly improved FMD and reduced 8isoprostane levels [32]. In hypertensive patients treated with zofenopril (15-30 mg/day, $n=15)$, ramipril $(2.5-5 \mathrm{mg} /$ day, $n=15)$, or atenolol $(50-100 \mathrm{mg} /$ day, $n=15)$ for 8 weeks, there was a similar improvement in FMD, but only zofenopril significantly reduced plasma hydroperoxides, 8 -isoprostanes, oxidized-LDL, and adhesion molecules [29]. Other trials have shown that NO, oxidative stress, and inflammatory markers can change in parallel with changes in FMD [17, 18, $22,23,27,29,32,35,38,41,43,46,51,52]$.

Angiotensin II causes vasoconstriction and increases the production of reactive oxygen species (ROS) by activating $\mathrm{NADH} / \mathrm{NADPH}$ oxidase through the angiotensin II type 1 receptor $[66,67]$. ARBs specifically bind to the angiotensin II type 1 receptor and inhibit vasoconstriction, fluid retention, and sympathetic nerve activity by blocking the effects of 
angiotensin II $[68,69]$. Furthermore, ARBs promote the activation of the angiotensin II type 2 receptor involved in NO production [70]. ARBs also decrease oxidative stress within the vessel wall by reducing the production of ROS and increasing NO production, which leads to improved endothelial function.

ACEIs block the RAAS and augment prostaglandins and the kallikrein-kinin system, and these effects lead to a decrease in blood pressure $[68,69]$. ACEIs also activate NO production through suppression of the degradation of bradykinin $[68,69]$. Whereas ACEIs are different from ARBs in their site of action, both drugs have a common action to inhibit the effects of angiotensin II $[68,69]$, and most studies showed that these two drug types improved endothelial function.

CCBs have antihypertensive effects that are mediated through the relaxation of vascular smooth muscle cells, and antioxidative effects that are mediated through an increased release of NO [71, 72].

$\beta$-blockers have scavenging activity for ROS, and these effects are possibly useful in preventing oxidative damage in HTN [73]. However, the improvement of FMD by $\beta$-blockers was not as great as that observed with other antihypertensive agents. Nebivolol, which is associated with NO-induced vasodilation, improved endothelial function more than other $\beta$-blockers.

Atherosclerotic risk factors such as diabetes mellitus and dyslipidemia also affect endothelial function, similar to HTN. These risk factors are often observed in patients with HTN. While the effects of these risk factors on FMD should be considered, specific trials for patients with diabetes mellitus or dyslipidemia were not included among the studies cited in the present paper.

\section{Perspective of Research on FMD in HTN}

HTN is a major atherosclerotic risk factor, and antihypertensive treatment protects against future cardiovascular events. The evaluation of endothelial function can be useful in the risk assessment of hypertensive patients treated with antihypertensive drugs. However, larger clinical trials that include morbidity and mortality as outcome variables are needed to further establish FMD as a prognostic marker in hypertensive patients. The influence of other atherosclerotic risk factors and confounding factors (such as obesity, diabetes, cigarette smoking, and dyslipidemia) on FMD in hypertensive patients should also be evaluated in future studies that attempt to establish the prognostic value of FMD. Furthermore, future studies should examine the association between the reduction in blood pressure and the improvement in FMD. In addition, changes in FMD should be compared with sonographical findings of carotid arteries, ankle brachial index, and pulse wave velocity, which have already been widely adopted as noninvasive methods to evaluate atherosclerosis.

\section{Conclusions}

The improvement of FMD in hypertensive patients is expected to slow the progression of atherosclerosis and improve long-term outcomes in these patients. The results of many but not all clinical trials suggest that there is a significant effect of antihypertensive therapy on FMD. ARBs and ACEIs appeared to improve FMD relative to other drug types. Antihypertensive treatment can generally improve endothelial dysfunction as assessed by FMD, although further research is needed.

\section{References}

[1] J. E. Deanfield, J. P. Halcox, and T. J. Rabelink, "Endothelial function and dysfunction: testing and clinical relevance," Circulation, vol. 115, no. 10, pp. 1285-1295, 2007.

[2] U. Landmesser and H. Drexler, "Endothelial function and hypertension," Current Opinion in Cardiology, vol. 22, no. 4, pp. 316-320, 2007.

[3] S. Nadar, A. D. Blann, and G. Y. H. Lip, "Endothelial dysfunction: methods of assessment and application to hypertension," Current Pharmaceutical Design, vol. 10, no. 29, pp. 3591-3605, 2004.

[4] A. S. de Vriese, T. J. Verbeuren, J. van de Voorde, N. H. Lameire, and P. M. Vanhoutte, "Endothelial dysfunction in diabetes," British Journal of Pharmacology, vol. 130, no. 5, pp. 963-974, 2000.

[5] J. Xu and M. H. Zou, "Molecular insights and therapeutic targets for diabetic endothelial dysfunction," Circulation, vol. 120, no. 13, pp. 1266-1286, 2009.

[6] R. Ross, "Atherosclerosis_an inflammatory disease," The New England Journal of Medicine, vol. 340, no. 2, pp. 115-126, 1999.

[7] F. Perticone, R. Ceravolo, A. Pujia et al., "Prognostic significance of endothelial dysfunction in hypertensive patients," Circulation, vol. 104, no. 2, pp. 191-196, 2001.

[8] M. G. Modena, L. Bonetti, F. Coppi, F. Bursi, and R. Rossi, "Prognostic role of reversible endothelial dysfunction in hypertensive postmenopausal women," Journal of the American College of Cardiology, vol. 40, no. 3, pp. 505-510, 2002.

[9] M. C. Corretti, T. J. Anderson, E. J. Benjamin et al., "Guidelines for the ultrasound assessment of endothelial-dependent flow-mediated vasodilation of the brachial artery: a report of the international brachial artery reactivity task force," Journal of the American College of Cardiology, vol. 39, no. 2, pp. 257265, 2002.

[10] D. S. Celermajer, K. E. Sorensen, V. M. Gooch et al., "Noninvasive detection of endothelial dysfunction in children and adults at risk of atherosclerosis," The Lancet, vol. 340, no. 8828, pp. 1111-1115, 1992.

[11] J. A. Whitworth, World Health Organization, and International Society of Hypertension Writing Group, "2003 World Health Organization (WHO)/International Society of Hypertension (ISH) statement on management of hypertension," Journal of Hypertension, vol. 21, no. 11, pp. 1983-1992, 2003.

[12] A. V. Chobanian, G. L. Bakris, H. R. Black et al., "The seventh report of the joint national committee on prevention, detection, evaluation, and treatment of high blood pressure: the JNC 7 report," The Journal of the American Medical Association, vol. 289, no. 19, pp. 2560-2572, 2003.

[13] E. J. Benjamin, M. G. Larson, M. J. Keyes et al., "Clinical correlates and heritability of flow-mediated dilation in the community: the framingham heart study," Circulation, vol. 109, no. 5, pp. 613-619, 2004.

[14] M. Juonala, J. S. A. Viikari, T. Laitinen et al., "Interrelations between brachial endothelial function and carotid intimamedia thickness in young adults: the cardiovascular risk in 
young finns study," Circulation, vol. 110, no. 18, pp. 2918 2923, 2004.

[15] S. Zaza, L. K. Wright-De Agüero, P. A. Briss et al., "Data collection instrument and procedure for systematic reviews in the Guide to Community Preventive Services," American Journal of Preventive Medicine, vol. 18, no. 1, supplement, pp. 44-74, 2000.

[16] M. L. Muiesan, M. Salvetti, C. Monteduro et al., "Effect of treatment on flow-dependent vasodilation of the brachial artery in essential hypertension," Hypertension, vol. 33, no. 1, part 2, pp. 575-580, 1999.

[17] D. Yavuz, M. Koç, A. Toprak et al., "Effects of ACE inhibition and AT1-receptor antagonism on endothelial function and insulin sensitivity in essential hypertensive patients," Journal of the Renin-Angiotensin-Aldosterone System, vol. 4, no. 3, pp. 197-203, 2003.

[18] D. C. Felmeden, C. G. C. Spencer, N. A. Y. Chung et al., "Relation of thrombogenesis in systemic hypertension to angiogenesis and endothelial damage/dysfunction (a substudy of the Anglo-Scandinavian Cardiac Outcomes Trial [ASCOT])," American Journal of Cardiology, vol. 92, no. 4, pp. 400-405, 2003.

[19] H. Tezcan, D. Yavuz, A. Toprak et al., "Effect of angiotensinconverting enzyme inhibition on endothelial function and insulin sensitivity in hypertensive patients," Journal of the Renin-Angiotensin-Aldosterone System, vol. 4, no. 2, pp. 119123, 2003.

[20] M. Munakata, A. Aihara, T. Nunokawa et al., "The influence of one-year treatment by angiotensin converting enzyme inhibitor on baroreflex sensitivity and flow-mediated vasodilation of the brachial artery in essential hypertensioncomparison with calcium channel blockers," Clinical and Experimental Hypertension, vol. 25, no. 3, pp. 169-181, 2003.

[21] L. Ghiadoni, A. Magagna, D. Versari et al., "Different effect of antihypertensive drugs on conduit artery endothelial function," Hypertension, vol. 41, no. 6, pp. 1281-1286, 2003.

[22] K. K. Koh, M. J. Quon, S. H. Han et al., "Additive beneficial effects of losartan combined with simvastatin in the treatment of hypercholesterolemic, hypertensive patients," Circulation, vol. 110, no. 24, pp. 3687-3692, 2004.

[23] K. K. Koh, S. H. Han, W. J. Chung et al., "Comparison of effects of Losartan, Irbesartan, and Candesartan on flowmediated brachial artery dilation and on inflammatory and thrombolytic markers in patients with systemic hypertension," American Journal of Cardiology, vol. 93, no. 11, pp. 1432-1435, 2004.

[24] S. Morimoto, Y. Yano, K. Maki, and K. Sawada, "Renal and vascular protective effects of telmisartan in patients with essential hypertension," Hypertension Research, vol. 29, no. 8, pp. 567-572, 2006.

[25] L. A. Souza-Barbosa, S. E. Ferreira-Melo, S. Ubaid-Girioli, E. Arantes Nogueira, J. C. Yugar-Toledo, and H. Moreno Jr., "Endothelial vascular function in hypertensive patients after renin-angiotensin system blockade," The Journal of Clinical Hypertension, vol. 8, no. 11, pp. 803-811, 2006.

[26] E. R. Mohler III, D. Herrington, P. Ouyang et al., "A randomized, double-blind trial comparing the effects of amlodipine besylate/benazepril $\mathrm{HCl}$ vs amlodipine on endothelial function and blood pressure," The Journal of Clinical Hypertension, vol. 8, no. 10, pp. 692-698, 2006.

[27] T. Oshima, R. Ozono, Y. Yano et al., "Beneficial effect of T-type calcium channel blockers on endothelial function in patients with essential hypertension," Hypertension Research, vol. 28, no. 11, pp. 889-894, 2005.
[28] L. Ghiadoni, D. Versari, A. Magagna et al., "Ramipril dosedependently increases nitric oxide availability in the radial artery of essential hypertension patients," Journal of Hypertension, vol. 25, no. 2, pp. 361-366, 2007.

[29] A. F. Pasini, U. Garbin, M. C. Nava et al., "Effect of sulfhydryl and non-sulfhydryl angiotensin-converting enzyme inhibitors on endothelial function in essential hypertensive patients," American Journal of Hypertension, vol. 20, no. 4, pp. 443-450, 2007.

[30] N. H. Buus, C. G. Jørgensen, M. J. Mulvany, and K. E. Sørensen, "Large and small artery endothelial function in patients with essential hypertension-effect of ACE inhibition and beta-blockade," Blood Pressure, vol. 16, no. 2, pp. 106-113, 2007.

[31] R. A. Benndorf, D. Appel, R. Maas, E. Schwedhelm, U. O. Wenzel, and R. H. Böger, "Telmisartan improves endothelial function in patients with essential hypertension," Journal of Cardiovascular Pharmacology, vol. 50, no. 4, pp. 367-371, 2007.

[32] A. J. Flammer, F. Hermann, P. Wiesli et al., "Effect of losartan, compared with atenolol, on endothelial function and oxidative stress in patients with type 2 diabetes and hypertension," Journal of Hypertension, vol. 25, no. 4, pp. 785-791, 2007.

[33] S. Morimoto, Y. Yano, K. Maki, and T. Iwasaka, "Renal and vascular protective effects of cilnidipine in patients with essential hypertension," Journal of Hypertension, vol. 25, no. 10, pp. 2178-2183, 2007.

[34] S. Morimoto, K. Maki, Y. Aota, T. Sakuma, and T. Iwasaka, "Beneficial effects of combination therapy with angiotensin II receptor blocker and angiotensin-converting enzyme inhibitor on vascular endothelial function," Hypertension Research, vol. 31, no. 8, pp. 1603-1610, 2008.

[35] Y. Hirooka, Y. Kimura, Y. Sagara, K. Ito, and K. Sunagawa, "Effects of valsartan or amlodipine on endothelial function and oxidative stress after one year follow-up in patients with essential hypertension," Clinical and Experimental Hypertension, vol. 30, no. 3-4, pp. 267-276, 2008.

[36] H. Korkmaz, I. Karaca, M. Koc, O. Onalan, M. Yilmaz, and M. N. Bilen, "Early effects of treatment with nebivolol and quinapril on endothelial function in patients with hypertension," Endothelium, vol. 15, no. 3, pp. 149-155, 2008.

[37] J. Yamada, H. Tomiyama, C. Matsumoto, M. Yoshida, K. Shiina, and A. Yamashina, "Effects of azelnidipine on the autonomic functions and its influence on arterial stiffness and endothelial functions," Journal of Cardiology, vol. 51, no. 2, pp. 114-120, 2008.

[38] K. Farkas, E. Fábián, and L. Nagy, "Quinapril improves endothelial function in postmenopausal hypertensive patients," Kidney and Blood Pressure Research, vol. 31, no. 4, pp. 226-233, 2008.

[39] R. Rossi, A. Nuzzo, G. Origliani, and M. G. Modena, "Metabolic syndrome affects cardiovascular risk profile and response to treatment in hypertensive postmenopausal women," Hypertension, vol. 52, no. 5, pp. 865-875, 2008.

[40] J. R. Jennings, M. F. Muldoon, J. Price, I. C. Christie, and C. C. Meltzer, "Cerebrovascular support for cognitive processing in hypertensive patients is altered by blood pressure treatment," Hypertension, vol. 52, no. 1, pp. 65-71, 2008.

[41] A. F. Pasini, U. Garbin, C. Stranieri et al., "Nebivolol treatment reduces serum levels of asymmetric dimethylarginine and improves endothelial dysfunction in essential hypertensive patients," American Journal of Hypertension, vol. 21, no. 11, pp. 1251-1257, 2008. 
[42] M. Kosch, A. Levers, D. Lang et al., "A randomized, doubleblind study of valsartan versus metoprolol on arterial distensibility and endothelial function in essential hypertension," Nephrology Dialysis Transplantation, vol. 23, no. 7, pp. 2280 2285, 2008.

[43] N. Merchant, C. D. Searles, A. Pandian et al., "Nebivolol in high-risk, obese African Americans with stage 1 hypertension: effects on blood pressure, vascular compliance, and endothelial function," The Journal of Clinical Hypertension, vol. 11, no. 12, pp. 720-725, 2009.

[44] A. D. Jung, W. Kim, S. H. Park et al., "The effect of telmisartan on endothelial function and arterial stiffness in patients with essential hypertension," Korean Circulation Journal, vol. 39, no. 5, pp. 180-184, 2009.

[45] S. Ubaid-Girioli, L. A. de Souza, J. C. Yugar-Toledo et al., "Aldosterone excess or escape: treating resistant hypertension," The Journal of Clinical Hypertension, vol. 11, no. 5, pp. 245-252, 2009.

[46] H. Yamanari, K. Nakamura, D. Miura, S. Yamanari, and T. Ohe, "Spironolactone and chlorthalidone in uncontrolled elderly hypertensive patients treated with calcium antagonists and angiotensin ii receptor-blocker: effects on endothelial function, inflammation, and oxidative stress," Clinical and Experimental Hypertension, vol. 31, no. 7, pp. 585-594, 2009.

[47] P. Perrone-Filardi, L. Corrado, G. Brevetti et al., "Effects of AT1 receptor antagonism with candesartan on endothelial function in patients with hypertension and coronary artery disease," The Journal of Clinical Hypertension, vol. 11, no. 5, pp. 260 265, 2009.

[48] L. Ghiadoni, A. Magagna, I. Kardasz, S. Taddei, and A. Salvetti, "Fixed dose combination of perindopril and indapamide improves peripheral vascular function in essential hypertensive patients," American Journal of Hypertension, vol. 22, no. 5, pp. 506-512, 2009.

[49] S. A. Brandão, M. C. Izar, S. M. Fischer et al., "Early increase in autoantibodies against human oxidized low-density lipoprotein in hypertensive patients after blood pressure control," American Journal of Hypertension, vol. 23, no. 2, pp. 208-214, 2010.

[50] M. I. Yilmaz, J. J. Carrero, J. L. Martín-Ventura et al., “Combined therapy with renin-angiotensin system and calcium channel blockers in type 2 diabetic hypertensive patients with proteinuria: effects on soluble TWEAK, PTX3, and flowmediated dilation," Clinical Journal of the American Society of Nephrology, vol. 5, no. 7, pp. 1174-1181, 2010.

[51] T. Wago, T. Yoshimoto, I. Akaza et al., "Improvement of endothelial function in patients with hypertension and type 2 diabetes after treatment with telmisartan," Hypertension Research, vol. 33, no. 8, pp. 796-801, 2010.

[52] S. Takiguchi, M. Ayaori, H. Uto-Kondo et al., "Olmesartan improves endothelial function in hypertensive patients: link with extracellular superoxide dismutase," Hypertension Research, vol. 34, no. 6, pp. 686-692, 2011.

[53] K. S. Heffernan, R. Suryadevara, E. A. Patvardhan, P. Mooney, R. H. Karas, and J. T. Kuvin, "Effect of atenolol vs metoprolol succinate on vascular function in patients with hypertension," Clinical Cardiology, vol. 34, no. 1, pp. 39-44, 2011.

[54] S. A. Hunt, D. W. Baker, M. H. Chin et al., "ACC/AHA guidelines for the evaluation and management of chronic heart failure in the adult: executive summary: a report of the American College of Cardiology/American Heart Association Task Force on Practice Guidelines (Committee to Revise the
1995 Guidelines for the Evaluation and Management of Heart Failure)," Journal of the American College of Cardiology, vol. 38, no. 7, pp. 2101-2113, 2001.

[55] B. M. Brenner, M. E. Cooper, D. de Zeeuw et al., "Effects of losartan on renal and cardiovascular outcomes in patients with type 2 diabetes and nephropathy," The New England Journal of Medicine, vol. 345, no. 12, pp. 861-869, 2001.

[56] UK Prospective Diabetes Study Group, "Efficacy of atenolol and captopril in reducing risk of macrovascular and microvascular complications in type 2 diabetes: UKPDS 39," British Medical Journal, vol. 317, no. 7160, pp. 713-720, 1998.

[57] F. Turnbull and Blood Pressure Lowering Treatment Trialists' Collaboration, "Effects of different blood-pressurelowering regimens on major cardiovascular events: results of prospectively-designed overviews of randomised trials," The Lancet, vol. 362, no. 9395, pp. 1527-1535, 2003.

[58] E. Braunwald, E. M. Antman, J. W. Beasley et al., "ACC/AHA 2002 guideline update for the management of patients with unstable angina and non-ST-segment elevation myocardial infarction-aummary article: a report of the American College of Cardiology/American Heart Association Task Force on Practice Guidelines (Committee on the Management of Patients with Unstable Angina)," Journal of the American College of Cardiology, vol. 40, no. 7, pp. 1366-1374, 2002.

[59] L. M. Prisant, "Nebivolol: pharmacologic profile of an ultraselective, vasodilatory $\beta$," Journal of Clinical Pharmacology, vol. 48, no. 2, pp. 225-239, 2008.

[60] M. L. Muiesan, M. Salvetti, A. Paini et al., "Prognostic role of flow-mediated dilatation of the brachial artery in hypertensive patients," Journal of Hypertension, vol. 26, no. 8, pp. 16121618, 2008.

[61] A. E. Donald, J. P. Halcox, M. Charakida et al., "Methodological approaches to optimize reproducibility and power in clinical studies of flow-mediated dilation," Journal of the American College of Cardiology, vol. 51, no. 20, pp. 1959-1964, 2008.

[62] L. Ghiadoni, D. Versari, C. Giannarelli, F. Faita, and S. Taddei, "Non-invasive diagnostic tools for investigating endothelial dysfunction," Current Pharmaceutical Design, vol. 14, no. 35, pp. 3715-3722, 2008.

[63] M. Charakida, S. Masi, T. F. Lüscher, J. J. P. Kastelein, and J. E. Deanfield, "Assessment of atherosclerosis: the role of flowmediated dilatation," European Heart Journal, vol. 31, no. 23, pp. 2854-2861, 2010.

[64] T. Asahara, T. Murohara, A. Sullivan et al., "Isolation of putative progenitor endothelial cells for angiogenesis," Science, vol. 275, no. 5302, pp. 964-967, 1997.

[65] A. Woywodt, F. H. Bahlmann, K. de Groot, H. Haller, and M. Haubitz, "Circulating endothelial cells: life, death, detachment and repair of the endothelial cell layer," Nephrology Dialysis Transplantation, vol. 17, no. 10, pp. 1728-1730, 2002.

[66] P. N. Seshiah, D. S. Weber, P. Rocic, L. Valppu, Y. Taniyama, and K. K. Griendling, "Angiotensin II stimulation of $\mathrm{NAD}(\mathrm{P}) \mathrm{H}$ oxidase activity: upstream mediators," Circulation Research, vol. 91, no. 5, pp. 406-413, 2002.

[67] K. K. Griendling, D. Sorescu, and M. Ushio-Fukai, "NAD(P)H oxidase: role in cardiovascular biology and disease," Circulation Research, vol. 86, no. 5, pp. 494-501, 2000.

[68] C. I. Johnston, "Angiotensin receptor antagonists: focus on losartan," The Lancet, vol. 346, no. 8987, pp. 1403-1407, 1995.

[69] T. L. Goodfriend, M. E. Elliott, and K. J. Catt, "Angiotensin receptors and their antagonists," The New England Journal of Medicine, vol. 334, no. 25, pp. 1649-1654, 1996. 
[70] A. Warnholtz, G. Nickenig, E. Schulz et al., "Increased NADHoxidase-mediated superoxide production. In the early stages of atherosclerosis evidence for involvement of the reninangiotensin system," Circulation, vol. 99, no. 15, pp. 20272033, 1999.

[71] A. Salameh, G. Schomecker, K. Breitkopf, S. Dhein, and W. Klaus, "The effect of the calcium-antagonist nitrendipine on intracellular calcium concentration in endothelial cells," British Journal of Pharmacology, vol. 118, no. 8, pp. 1899-1904, 1996.

[72] R. Berkels, G. Egink, T. A. Marsen, H. Bartels, R. Roesen, and W. Klaus, "Nifedipine increases endothelial nitric oxide bioavailability by antioxidative mechanisms," Hypertension, vol. 37, no. 2, pp. 240-245, 2001.

[73] A. Gomes, D. Costa, J. L. F. C. Lima, and E. Fernandes, "Antioxidant activity of $\beta$-blockers: an effect mediated by scavenging reactive oxygen and nitrogen species?" Bioorganic and Medicinal Chemistry, vol. 14, no. 13, pp. 4568-4577, 2006. 


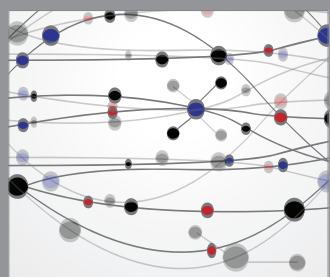

The Scientific World Journal
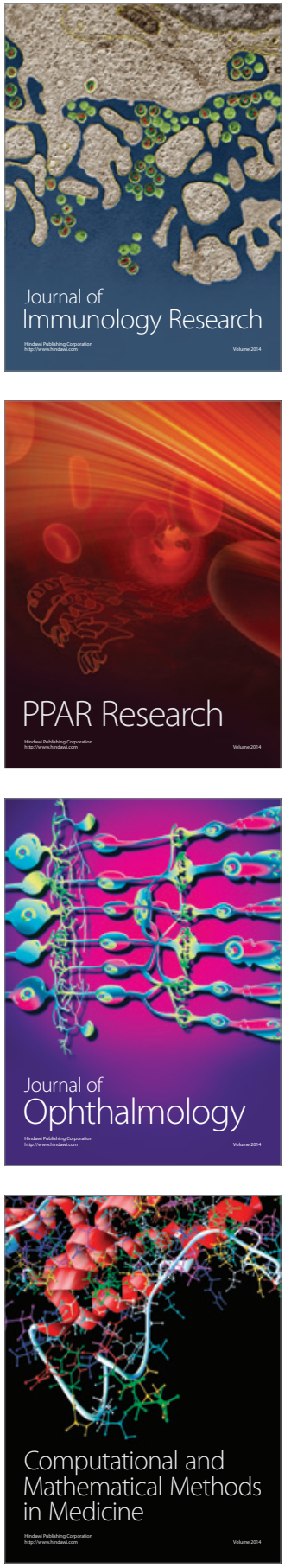

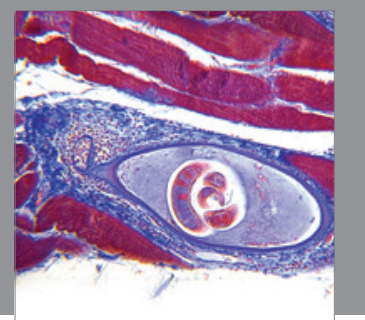

Gastroenterology

Research and Practice
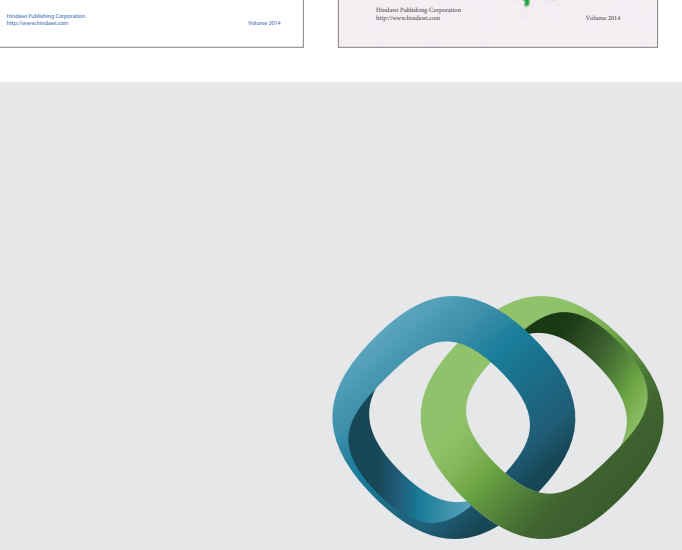

\section{Hindawi}

Submit your manuscripts at

http://www.hindawi.com
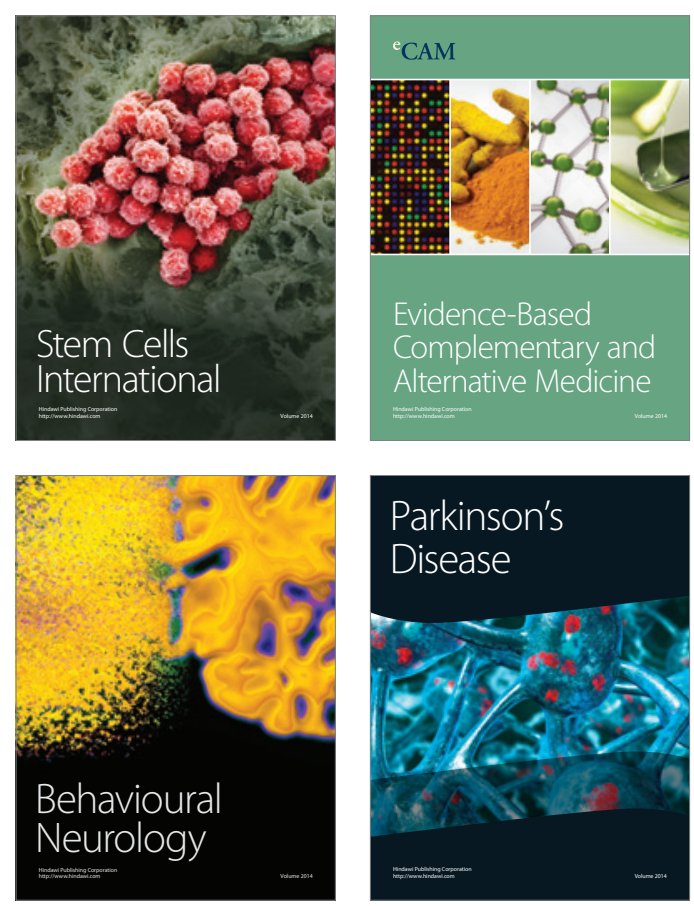

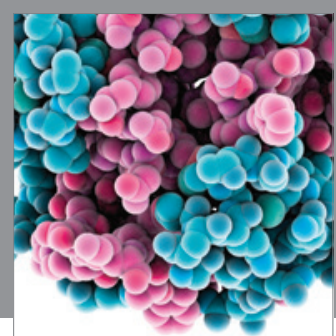

Journal of
Diabetes Research

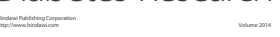

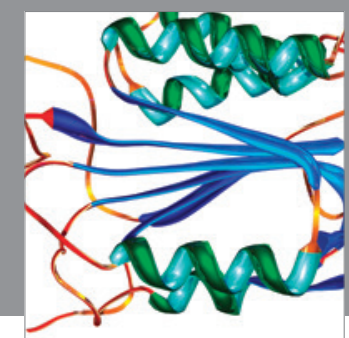

Disease Markers
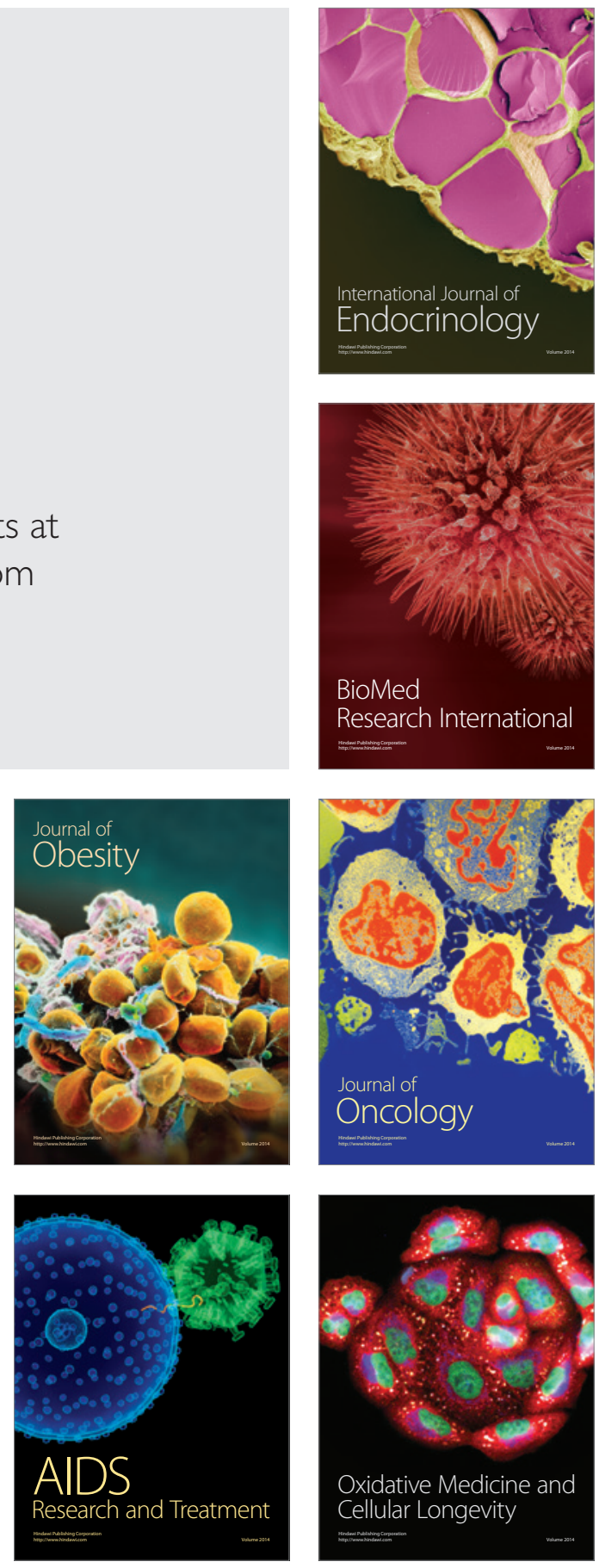